Citation: Data-Bukowska, E. (2019). Coming nearer and nearer: A cognitive grammar account of the third person plural impersonal. Cognitive Studies / Études cognitives, 2019(19). https://doi.org/10.11649/cs.1752

\title{
EWA DATA-BUKOWSKA
}

Jagiellonian University, Cracow, Poland

ewa.data-bukowska@uj.edu.pl

https://orcid.org/0000-0002-8105-235X

\section{COMING NEARER AND NEARER: A COGNITIVE GRAMMAR ACCOUNT OF THE THIRD PERSON PLURAL IMPERSONAL}

\begin{abstract}
The present paper analyzes different readings of the 3pl impersonal pronoun (3pl IMP) from the Cognitive Grammar (CG) perspective. While the well-known taxonomy established for 3pl impersonals in European languages by Siewierska \& Papastathi (2011) highlights contextual features of different readings of the pronoun, CG is able to focus on what has been neglected in this approach and offers a more adequate analysis of the 3pl IMP as an important means of portraying the agent. In the article the impersonal agent is presented as unspecified and, as such, defocused to various degrees. Evidence is provided for a set of four prototypical readings of the pronoun - the corporate, the vague, the specific and the universal - constituting reference points within a continuum and differentiated as to the agent portrayal. Establishing such portrayals is seen as a phenomenon rooted in the cognitively basic mechanism of distancing, which in the case of the 3pl IMPs means approaching the perceived object by the conceptualizer, as in the schema underlying the difference between a count noun and a mass noun. The mechanism is illustrated by language data taken from English and Swedish.
\end{abstract}

Keywords: agent defocusing; impersonals; distancing; Swedish/English

\section{Introduction}

According to Langacker $(2009,2011)$, impersonal constructions are important means of linguistic imagery because they allow the conceptualizer $(\mathrm{C})$ to portray the agent in a sentence in a particular manner. However, while full nominals characterize the agent in detail, impersonals leave this main participant in an action chain unspecified, making it less prominent (Langacker, 2011, p. 185). An unspecified agent may be variously interpreted depending on the pronouns used, as demonstrated in (1) below. This paper focuses on the $3 \mathrm{pl}$ pronoun represented by such items as English they or Swedish de/dom, used impersonally, as in (1b). 
(1) a. Man har anordnat en fest nu igen. One has organized a party again.

b. Dom har anordnat en fest nu igen. They have organized a party again.

c. Folk har anordnat en fest nu igen. People have organized a party again.

d. Det har anordnats en fest nu igen. There has been organized a party again. ${ }^{1}$

(see Teleman, Hellberg, \& Andersson, 1999, p. 286)

In typological research an inventory of impersonal readings of the $3 \mathrm{pl}$ has been identified. They are mainly characterized on contextual grounds and attested in many different languages as instances of the so-called third person plural (3pl) impersonal construction (Siewierska, 2008, p. 6). However, a definitive semantic description based on conceptual criteria has not yet been established for such instances. For this reason, the present paper aims to take a stance on the following issues:

How are the identified types of impersonal readings of the $3 \mathrm{pl}$ represented conceptually in respect to the agent defocusing, as seen from the perspective of Cognitive Grammar (CG), and which cognitive processes may underlie the development of such readings?

Thus, the present article demonstrates how different readings of the $3 \mathrm{pl}$ impersonal construction emerge as special cases from cognitive roots. It focuses on, as Siewierska expresses it, "events which may be brought about by a human agent but crucially one which is not specified" (Siewierska, 2008 , p. 4). However, it is taking a clearly agent-centered perspective on this topic. The impersonal agent, as a non-specific controller of the action expressed by the predicate, is seen as defocused to various degrees.

Presenting the issue from the CG perspective may lead to a revision of scholars' understanding of the 3pl IMP reference as such. According to Myhill (1997, p. 799), one of the pioneers in the research on IMPs, it is desirable to identify some general cognitive structures which may underlie the phenomenon of agent defocusing. Yet, as he points out, this will not be possible "until we have a better understanding of cross-linguistic variation in the factors controlling agent defocusing" (Myhill, 1997, p. 799, emphasis E.D.-B.). ${ }^{2}$ Identifying such cognitive structures in the manner proposed by Myhill is only partly satisfactory, which will be demonstrated by discussing the taxonomy for the 3pl IMP compiled by Siewierska and Papastathi (2011) and widely applied in typological research (e.g. Gast, 2015; Gast \& van der Auwera, 2013; Siewierska, 2011). Because CG is deeply rooted in psychological knowledge pertaining to cognition, it allows for the description of such structures from a different angle, i.e. by analyzing conceptual images of the agent portrayed by the $3 \mathrm{pl}$ pronoun in its different impersonal uses. In what follows, this procedure will be demonstrated on the basis of an analysis of linguistic expressions in English and Swedish. ${ }^{3}$ In this way the present article will propose a modified, more strongly cognitively-based account of the taxonomy of the $3 \mathrm{pl}$ IMPs in language.

\section{The 3pl IMPs from a typological perspective}

A model for a typology of 3pl IMPs is presented in Siewierska and Papastathi (2011). It is based on the pioneering work of Myhill (1997) and Cabredo Hofherr (2003, 2006) and aims to establish the basis for a more thorough investigation of such items in a sample of European languages.

A characteristic feature of the $3 \mathrm{pl}$ IMPs is the lack of an overt antecedent in the preceding text/discourse. Therefore, when seen from the traditional grammar perspective, they are by no means anaphoric. Neither are they deictic, because they do not refer to an antecedent present in the immediate context of communication. The only type of reference that can be considered for

\footnotetext{
${ }^{1}$ Unless otherwise noted, all translations from Swedish into English in the paper are the author's own (E.D.-B.).

2"It would be premature to attempt to posit general human cognitive structures accounting for agent defocusing as a general phenomenon, until we have a better understanding of cross-linguistic variation in the factors controlling agent defocusing" (Myhill, 1997, p. 799).

${ }^{3}$ For a more thorough description of the 3pl IMPs in Swedish see Data-Bukowska (2018).
} 
these expressions is Deixis am Phantasma, as defined by Bühler (1934/1982), when the referent may be identified on the basis of the speakers' shared knowledge and imagination.

According to Cabredo Hofherr (2003, p. 83), five different types of impersonal readings (branded by her as antecedentless readings) of the $3 \mathrm{pl}$ pronouns can be distinguished:

(I) specific existential reading (temporally anchored):

a. Tocan a la puerta.

(They) knock.3pl at the door. (= someone is knocking...)

(II) vague existential reading (not temporally anchored):

b. Han encontrado una motocicleta en el patio.

(They) have.3pl found a motorbike in the courtyard.

(III) inferred existential reading (inferred from a result):

c. Aquí han comido mariscos.

Here, (they) have.3pl eaten seafood. (= someone)

(IV) corporate reading (predicates with a designated subject)

d. Volvieron a aumentar el IVA.

(They) raised VAT again.

(V) universal reading (licensed by a locative):

e. En España hablan español.

In Spain, (they) speak.3pl Spanish.

Cabredo Hofherr (2003, p. 83)

From the point of view of Siewierska and Papastathi (2011), six different types of impersonal readings of the $3 \mathrm{pl}$ pronouns can be distinguished. These readings may be ordered on semantic grounds as follows:

a) universal, e.g. In Spain, they eat late.

b) corporate, e.g. They changed the tax laws last year.

c) vague existential, e.g. They've found his bike in the back of a barn.

d) inferred existential, e.g. They've been frying chips here.

e) specific existential, e.g. They're knocking on the door.

f) the speech act verb say construction, e.g. They say he met vampires in the Black Forest.

(Siewierska \& Papastathi, 2011, pp. 581, 584)

By presenting their modified account of the typology of the 3pl IMPs, Siewierska and Papastathi (2011) attempt to unify the model of Cabredo Hofherr (2003), because, as they point out, it is based on disparate criteria (Siewierska \& Papastathi, 2011, p. 584). The characteristics of the six types of 3pl IMPs with respect to the criteria discussed by Siewierska and Papastathi (2011) are summarized in Table 1 below.

In determining a particular type of reading, Siewierska and Papastathi (2011) firstly take into consideration the contextual conditions influencing the interpretation of the 3pl IMP. In their view, the degree of agent identification in the three types of reading (the universal, the corporate, the vague) is connected with the presence of some more or less clearly marked features of the context: a locative expression (in the universal reading), the verb that profiles an action dependent on a group conducting it (in the corporate reading), and no such distinct features (in the vague reading) (Siewierska \& Papastathi, 2011, p. 584). 
Table 1: Characteristics of the 3pl IMPs (Siewierska \& Papastathi, 2011, p. 583, with modifications by E.D.-B.)

\begin{tabular}{|l|c|c|c|c|c|c|}
\hline Property & universal & corporate & vague & inferred & specific & 'say' \\
\hline Necessary group identification & + & + & - & - & - & + \\
\hline Delimitation of group by locative & + & - & - & - & - & - \\
\hline Delimitation of group by predicate & - & + & - & - & - & + \\
\hline Anchoring in time & - & + & $(+)$ & + & + & - \\
\hline Specific time reference & - & - & - & - & + & - \\
\hline Inferred by result & - & - & - & + & - & - \\
\hline
\end{tabular}

The contextual conditions enabling the agent to be distinguished are also exposed in the description of other types of 3pl IMPs. As the scholars point out, the inferred and specific readings are connected to agent identification, mainly based on situational grounds. The situational context enabling this identification is a physical perception of something that can be treated as a result of a previously occurred event (in the inferred existential reading). Taking into consideration such perceptions as e.g. a smell, taste, sound, damage, etc., the speaker connects them with the agent, who may be either known or unknown. On the other hand, in the specific existential reading physical contact with the agent seems to be the basis of identification. This contact can be visual (at the door, on TV), acoustic (on the phone, on the radio), written (via an e-mail or a letter) etc. (Siewierska \& Papastathi, 2011, p. 584). The same way of thinking is present in distinguishing the additional sixth type of impersonal readings of the $3 \mathrm{pl}$ pronoun by Siewierska and Papastathi (2011). They state that sentences including the verb say express a general truth, which may be seen as a kind of vague reading. The main reason for distinguishing this reading is, however, the fact that it may be the only type that is allowed in some languages (e.g. Finnish or Estonian) (Siewierska \& Papastathi, 2011, p. 584).

The characteristics pertaining to the agent itself in Siewierska's and Papastathi's taxonomy are mainly based on whether it may be interpreted as a single individual or as a group. Practically, this means that the $3 \mathrm{pl}$ pronoun can potentially be paraphrased with someone, which is possible in existential readings but not in the universal reading, the corporate reading, and the say-construction. In these three types, an important feature of the agent is its group identification. The agent is simply a member of a collective (Siewierska \& Papastathi, 2011, p. 581).

On the other hand, a deeper analysis of all the impersonal readings of the $3 \mathrm{pl}$ conceived in the taxonomy by Siewierska and Papastathi (2011) leads to the conclusion that the description of the vague existential reading is the most imprecise of all the proposed types (see Table 1 above). According to the scholars, the only defining feature that should be present in distinguishing this reading - 'anchoring in time' - is excluded by Cabredo Hofherr (2003). On the other hand, as Cabredo Hofherr (2003, p. 86) points out, this reading does not imply plurality. However, this observation would appear to be an overgeneralization.

It is not difficult to notice that in the sentence cited above, They've found his bike in the back of a barn, the agent may take more varied interpretations than the suggested implied 'someone'. As Siewierska and Papastathi (2011, p. 581) remark, "a paraphrase with someone may be attributed to the fact that in the absence of any information about the referent of the subject, the possibility of the referent being a single individual cannot be excluded." However, plurality is profiled by the $3 \mathrm{pl}$ pronoun, and this content cannot be abolished within the conceptualization in which no other specific clues are provided for the agent identification. Due to the 3plIMP's meaning, the agent can be then imagined as more than one individual, but not necessarily a group of cooperating individuals who perform the action together (as in the corporate reading). 
Given these characteristics, a certain variation may be indentified within the 3pl IMP construction, which can be treated as a category of subconstructions depending on particular contextual conditions.

Siewierska and Papastathi (2011, p. 584) point out that their unification of the typology of the 3pl IMPs is construed along the lines presented within the Cognitive Linguistic research by Langacker $(2004,2006 \mathrm{a})$. This, however, is more postulated than factual. By mentioning the characteristics of context that enable one to distinguish particular types of the $3 \mathrm{pl}$ IMP, the researchers only partially accomplish the goals of CG. They do not explain how the agent is portrayed within the featured types of readings or how such agent profiles are interconnected conceptually. Moreover, a cognitive motivation underlying the appearance of such portrayals something that, according to CG, is an essential part of a linguistic description - is not taken into account by Siewierska and Papastathi. Consequently, the proposed description of the 3pl IMPs does not concern, as Langacker (2006a) suggests, different degrees of agent defocusing as seen by a conceptualizer. Thus, the comprehensive listing of the $3 \mathrm{pl}$ readings does not reveal the cognitive roots of the functioning of the construction and its variants in different languages. In what follows, this issue will be examined from the $\mathrm{CG}$ perspective.

\section{Meaning from the perspective of Cognitive Grammar}

When describing the meaning of the 3pl IMP from the perspective of CG (Langacker, 2009, p. 110) the very first question one should ask is: What does the $3 \mathrm{pl}$ pronoun in its impersonal use mean, not only in relation to other impersonals, but also within its category (in the item's different readings)? To understand this prerequisite, some assumptions of CG must be outlined.

Within the CG tradition (Langacker, 1987, 1991) categories are viewed in terms of prototype structure and family resemblance. Taking into account this approach, it can be stated that the above-mentioned types of readings of the $3 \mathrm{pl}$ IMP can be treated as a radial category containing a center and a periphery and differentiated at the level of the image of the defocused agent. Additionally, they represent a given network, within which some nodes may be seen as more prototypical reference points for new meanings. Finally, since in the cognitive vision of language the boundaries between categories are seen as fuzzy, particular nodes within the 3pl IMP network may overlap with each other on the edges and merge smoothly with one another. This means that not only defocusing, but also the agent itself, should be treated as scalar.

$\mathrm{CG}$ adopts a conceptual view of meaning, which is defined as conceptualization, i.e. "a conceptual structure that functions as the semantic pole of a linguistic expression" (Langacker, 1987, p. 98). However, due to this view, the meaning of an expression is not only a matter of the conceptual content that it evokes, but is also dependent on the construal which the linguistic structure imposes on that content. The center of a linguistic conceptualization is, therefore, a conceptualizer (usually the speaker), who is responsible for creating such "mental pictures". It is him/her who decides which aspects of a situation are highlighted (profiled) and which are backgrounded within a conceptualization (Langacker, 1987, pp. 110, 136).

Moreover, a major claim of $\mathrm{CG}$ is that the meaning of a linguistic structure is contextual. Langacker (1987, p. 157) describes it as "the richly detailed conceptualization that constitutes our full understanding of the expression in context and includes all relevant aspects of the conceived situation". It is encyclopedic and cannot be reduced to the content of its constitutive individual lexical items.

The so-called base of a linguistic structure (or its scope) is provided by conceptual content that is evoked by this expression in a particular context. Upon such a base the expression imposes a profile that is the focal point within the conceptualization. It can then be said that the base constitutes the context that is necessary for distinguishing the profile (the figure) (Langacker, 1987 , p. 118). However, designation is always a result of interaction between the profile and the base (Langacker, 1987, p. 187). In the case of 3pl IMPs, it is the interaction between the schematic 
profile of the $3 \mathrm{pl}$ pronoun and the contextual features which are presented for European languages in Table 1 above. In this respect, all contextual characteristics listed in Table 1 can be seen as influencing the appearance of the agent - the most prominent participant in the action chain, profiled by the pronoun. ${ }^{4}$

Additionally, many aspects of meaning construal in CG pertain to the perspective taken on the scene (the conceptual content) (Langacker, 1987, p. 120). An important constituent of this dimension of construal is the vantage point (i.e. the position from which the scene is viewed) that is presupposed by the conceptualizer (Langacker, 1987, p. 123ff). For example, the conceptualizer may maintain his/her own vantage point within the conceptual picture (e.g. the verb come) or adopt the vantage point of the listener (e.g. the verb go). Similarly, the conceptualizer may be present within the linguistic image or see the whole situation from the outside. However, this does not deprive him/her of the possibility of conceiving the scene from different distances, which, as Langacker (1987, p. 181) points out, have "far-reaching implications for linguistic analysis", extending from the purely spatial domain to more abstract ones. The following excerpt from Langacker (2006b, p. 122) illustrates differences in distance/proximity to the perceived situation as reflected in language structures representing a count noun and a mass noun:

Viewed from the top of a distant hill, Lakoff's cows present themselves as a continuous patch of brown perceived against the landscape. Since the patch is bounded, we can label it with a count noun, namely herd. When we view the herd from closer range, we lose sight of its boundaries and also resolve the continuous mass into discrete particles. Here we use a plural like cows, which designates a particular mass. If we zoom in further and focus on a single particle, the applicable term is a singular count noun, such as cow. When I move in for a closer look, and press my nose against the side of the cow, I lose sight of its overall contour - all I see is cowhide, a continuous substance. At a higher resolution I can see that the visible surface of the hide is densely covered by hairs, and if I focus on just one I am looking at a hair. And so on.

According to CG, distinguishing particular words in a language is based on the human cognitive ability to see the same object from a different distance. In English, different portrayals of such an object have been conventionalized in the form of language items such as herd, cows, a cow and, if it is necessary, cowness (i.e. "the quality of being a cow"). ("Cowness", n.d.)

Another important dimension of construal, strictly connected to distance/proximity, is the level of specificity (or schematicity) chosen for the characterization of a given entity. Each entity may be characterized either in detail or more schematically. The precision of linguistic classification provided by a noun (a type) within a conceptualization can therefore be characterized in a finegrained (detailed) or a coarse-grained (schematic) manner, as in rattlesnake or snake (Langacker, 1987, pp. 91, 117). The same pertains to all linguistic conceptualizations.

\section{Dimensions of agent defocusing in CG}

According to Langacker (2006a), some of the dimensions of construal can be applied to describe agent defocusing.

The agent is defined by Langacker (2006a, p. 118) on semantic (i.e. conceptual) grounds as "a more active participant in an action chain" or as "an energy source". Usually, it is coded by the subject in the clause, but it does not have to be. In a sentence, however, the notion of an agent is always invoked. It can be maximally unspecified (and not expressed linguistically) in the conceptualization, as is often the case in the passive construction, which is used when responsibility for the action cannot be assigned to any individual. In such situations "no indication is given of how that role of the agent is filled" (Langacker, 2009, p. 115). On the other hand, as Langacker (2009, p. 115) remarks, one can imagine a class of possible candidates that may fill the role

\footnotetext{
${ }^{4}$ Profiling is indicated by means of heavy lines in all Figures presented in the article.
} 
of the agent. Practically, this means that any entity conceived of as a [thing] (i.e. something) may be applied in this position. The portrayal of such an energy source may also be blurred or underspecified, if some strategies of defocusing are applied.

According to Langacker (2006a, 2009, 2011), agent defocusing may be nuanced with respect to such dimensions as degrees of referentiality (pertaining to whether the profiled noun is grounded, i.e. related to the speakers' here and now) and specificity. The present article is not going to deal with the former dimension in detail. It can only be added that the $3 \mathrm{pl}$ (similarly to other personal pronouns) is a grounded predication. This can be explained with reference to the fact that object identification by the use of such pronouns is always possible thanks to the interlocutors' agreement within their shared knowledge (their common ground).

While focusing on specificity in the description of the 3pl IMPs, it is to be stressed that a constant departure point for each strategy of defocusing is the optimal viewing arrangement, in which the energy source (the agent) is "a single, clearly delimited, fully identified individual put onstage as a specific focus of attention" (Langacker, 2006a, p. 130), as in the examples in (2) below.

(2) That vagrant found his bike in the back of a barn.

Jonathan has been frying chips here.

According to Langacker (2009, p. 123, 2011, p. 192), another particularly important dimension connected to agent defocusing is that of delimitation. ${ }^{5}$ This notion pertains to how much of the relevant universe of discourse the profiled instance (the referent) subsumes (or delimits). As Langacker points out, "delimitation involves the size (or extension) of that instance" (Langacker, 2011, p. 192). In the examples in (2) the agents are clearly delimited in space, but delimitation can also occur within other, more abstract domains.

Alternatively, delimitation of the agent may be portrayed less precisely. Langacker (2009, p. 124 ) adds that a good example of items that vary as to their degree of delimitation are the deictic adverbs here and now, which, depending on the context, can pertain to a quite narrow space around the speaker or to the whole universe. The $3 \mathrm{pl}$ behaves in a similar way. In its impersonal uses no specific individuals are singled out by the pronoun (Langacker, 2009, p. 125). Additionally, the delimitation of such individuals can be displayed in different manners as to the extension or size of the referent within the conceptualization (Langacker, 2011, p. 193).

\section{The 3pl IMP from the CG perspective}

\subsection{The corporate reading}

In the case of the $3 \mathrm{pl}$ pronoun the conceptualizer (usually the speaker) always takes an outside position relevant to the conceived situation. The addressee is also excluded from the conceptual picture. By its semantic content, the pronoun indicates a plural object [thing]. Moreover, it seeks such an object in the available context. In prototypical anaphoric reference the pronoun is definite because it singles out a unique plural referent which has been previously mentioned and, as such, is known to the interlocutors. In this respect the object is also treated as clearly delimited, e.g.

(3) Jag träffade hans mor, hans far och hans syster i staden igår. De var mycket glada.

I met his mother, his father and his sister in the city yesterday. They were very happy.

This type of situation is illustrated in Figure 1 below.

The mechanism of prototypical anaphoric reference (Fig.1) can be seen as a conceptual departure point for different, less prototypical readings of the $3 \mathrm{pl}$ pronoun.

\footnotetext{
${ }^{5}$ Langacker points out that delimitation is to be seen as different from selection i.e. choosing a referent (an instance of an object) (Langacker, 2011, p. 192).
} 


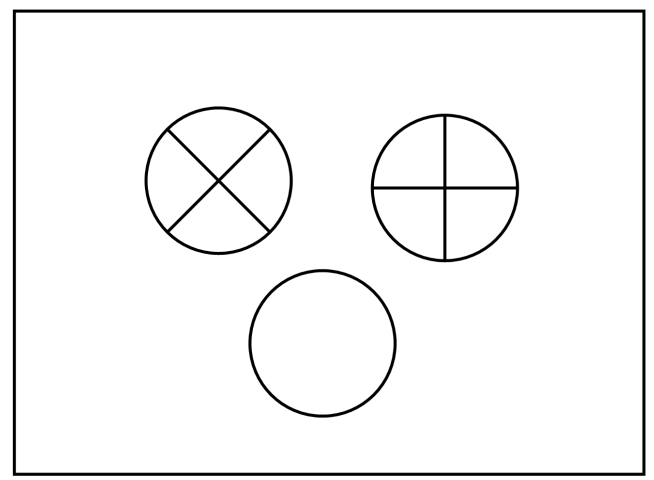

ans mor, hans far och hans syster 'his mother, his father and his sister'

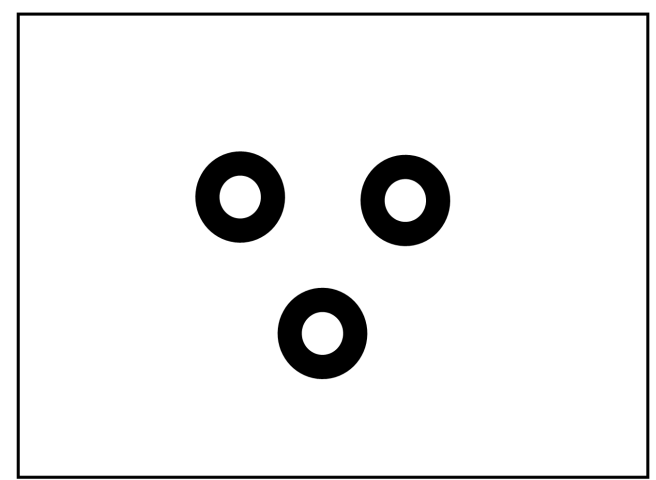

$\mathrm{de} / \mathrm{dom}$

'they'

Figure 1: Anaphoric plural reference

However, it should also be added that in each language a plural object may be conceived of as a collective (designated by a noun) if the conceptualizer is able to identify some interconnections among particular individuals. This can be seen in the case of such nouns as team, family, class, or even archipelago, as illustrated in Figure 2.

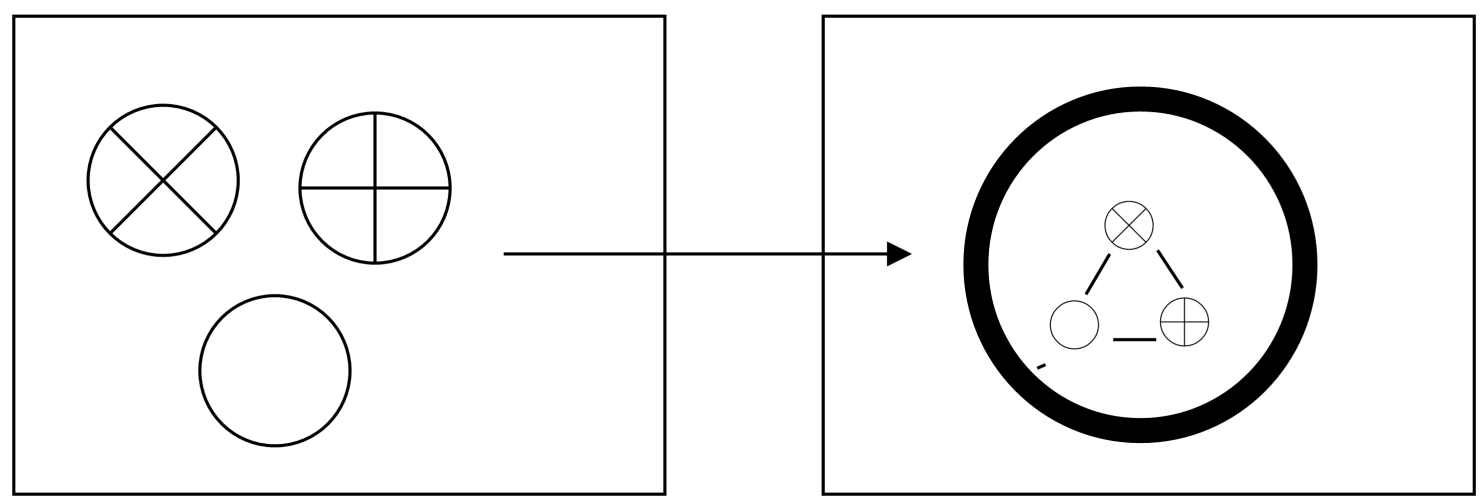

Figure 2: A collective object, e.g. family

According to Langacker (1987, pp. 196-197,), conceptual contents in such cases are defined in an abstract domain that can be described as "cooperative activity towards a common objective". The result is that the designated object (a region) is delimited from its surroundings so that it does not extend indefinitely. It is always fully included in the scope of predication (the base), which means that it is perceived as a coherent gestalt against a ground - Fig. 2. In Langacker's terms (Langacker, 1987, pp. 192-193) it is bounded, although at first glance its boundaries may seem unclear. On the other hand, such an object may also imply plurality, which can potentially be applied as a basis for reference. A concise explication of this issue can be found in the comprehensive grammar of the Swedish language, Svenska Akademiens Grammatik (SAG) (Teleman et al., 1999).

In the SAG (Teleman et al., 1999, p. 286), pronominal reference to collective antecedents is conceived of as the so-called indirect anaphor, as in the examples in (13) below: 
I hans familj gick de och la sig tidigt. Regeringen ... de vill införa en ny skatt.

På invandrarverket vill de ännu inte göra något uttalande. (Teleman et al., 1999, p. 395)
In his family they used to go to bed early.

The government ... they want to introduce a new tax.

At the immigration office they do not want to make a statement.

Such uses of the $3 \mathrm{pl}$ pronoun in Swedish are seen by the SAG as marginal. However, they clearly show a gestalt concept (seen as a kind of corporation) acting as a reference point for the pronominal reference. The same object may thus be seen to be on different levels of conceptual organization, both as a group or as individuals constituting this group, even though the character of the gestalt is sketched only briefly in the preceding context, as in (5) below.

Det är olagligt att sälja krockade bilar på detta sättet, från USA via Litauen till Sverige. Detta togs upp i en artikel i tidningen Teknikens Värld för några månader sen. Dom intervjuade en kille på Krim som enbart arbetar med fordon och enligt honom är det förbjudet (Mr_Big, 2012).
It is illegal to sell crashed cars in this way, from the United States via Lithuania to Sweden. This was mentioned in an article in the magazine Teknikens Värld a few months ago. They interviewed a guy on Crimea who only works with vehicles and according to him it is forbidden.

Moreover, Langacker (2011, p. 192) points out that personal pronouns often do not require an overt antecedent. Nevertheless, a referent that is not mentioned contextually may be evident to the interlocutors, as is shown in example (6), where the object thieves is clearly implied and may be confirmed by language users.

$$
\begin{aligned}
& \text { Min sambo har blivit bestulen på } \\
& \text { sina nycklar, när han var inne i city. } \\
& \text { Plånboken tog dom tack och lov } \\
& \text { inte ("Täcker hemförsäkringen stulna } \\
& \text { nycklar?", 2010). }
\end{aligned}
$$

My partner has been robbed of his keys when he was in town. Luckily, they didn't take his wallet.

Taking these facts into account, it may be concluded that the best candidate for a departure point in a description of agent defocusing by the $3 \mathrm{pl}$ is the corporate reading of the pronoun, which can be explained on a cognitive basis. A gestalt is always more prominent than its constituting parts. It is also seen as singular and discrete. Due to its schematic content (i.e. corporate constituents), it is also easy to evoke. As it is automatically distinguished from the ground, it can be referred to easily. Langacker (2006a, p. 134) points out that "[f]ocal prominence tends to be conferred on entities that are discrete, compact, well-delimited, and clearly identified".

In the case of impersonal readings of the 3 pl pronoun mentioned in Table 1 above, no reference point for establishing the agent occurs in the preceding context. However, an image of such an entity is present in the speakers' consciousness as a constituent of an evoked frame. The so-called corporate reading of the $3 \mathrm{pl}$ IMPs is thus based on the same entrenched cognitive operation as the examples in (4) above. In a contextually construed frame, a few representatives are seen as a whole conducting a "cooperative activity towards a common objective", which is a sufficient condition for pronominal reference, as illustrated in (7). 


$$
\begin{aligned}
& \text { Ytterligare en skatt på elektronik... } \\
& \text { vad håller de på med? } \\
& \text { Vi i Sverige betalar redan premium } \\
& \text { priser på datorer, tv apparater, spel } \\
& \text { konsoler och datorkomponenter i jäm- } \\
& \text { förelse med många länder. De tröck } \\
& \text { ju även in skatt på hur mycket lagring } \\
& \text { man har och nu på vikten av grejerna. } \\
& \text { Nånstans måste det väl ta stopp [...] } \\
& \text { ("Ytterligare en skatt på elektronik... } \\
& \text { vad håller de på med?", 2017). }
\end{aligned}
$$

An additional tax on electronics ... what are they doing?

We in Sweden already pay premium prices on computers, TVs, game consoles and computer components in comparison to many countries. They also charge taxes on how much storage you have and now on the weight of the stuff. It must stop somewhere [...].

Within the evoked frame the referent is clearly the Swedish government - a fact that anyone in a position to assess may confirm by taking into account contextual information.

Construing this type of agent is possible only if special conditions are fulfilled. It can be observed that the plural object presents itself as a gestalt against a background if it is viewed from a distant position. It is present in the conceptualizer's field of view as a whole so that $\mathrm{s} / \mathrm{he}$ can see its borders (delimitation). Individual participants constituting the gestalt are only present in the base of the conceptualization. Note that they are members of the same category (e.g. people), but they do not have to be identical. The profile of the agent in the corporate impersonal reading of the $3 \mathrm{pl}$, as in (5), can therefore be compared to the construction of the noun herd in the description of Lakoff's cows. Figure 3 below illustrates this type of agent construal:

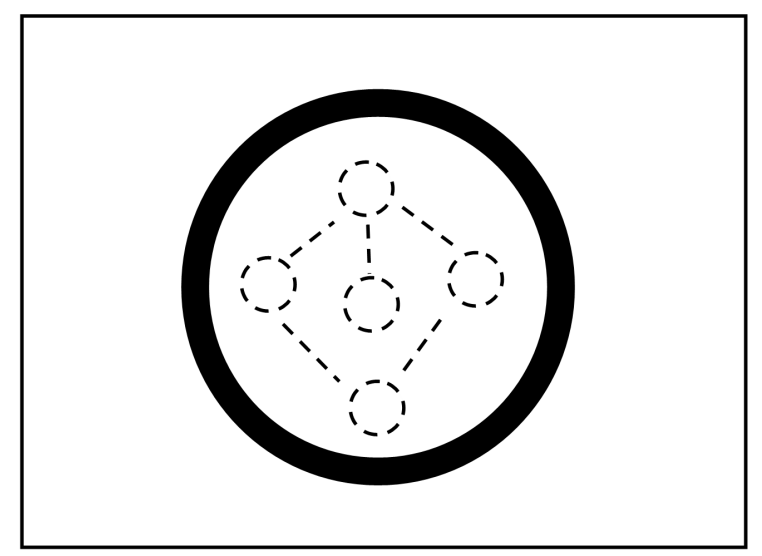

Figure 3: The profile of the agent in the corporate reading of the 3pl IMP

\subsection{The vague reading}

Fig. 3. illustrates a plural object conceived of as a collective, because language users have decided that interconnections among some individuals are a relevant aspect of the perceived situation. It may be added at this point that when this plural object is viewed from a closer range, the relations (interconnections) among the participants can be seen more clearly. These relations are implied to a different degree in particular instances of the corporate 3pl IMP in concrete conceptualizations. On the other hand, while approaching such an object one can also lose sight of its boundaries and resolve the gestalt into discrete elements. In conceptual terms, seeing the individuals in the group, and not the group as a whole, means moving nearer to the perceived object, construing it as a countable noun in the plural form (like cows in Lakoff's example) profiling a particular (or 
granulated) mass $^{6}$ present within the conceptualizer's field of view. This kind of conceptual picture of the defocused agent is typical for the vague existential and inferred existential readings of the $3 \mathrm{pl}$ IMP. They differ in terms of contextual conditions, but not in terms of the character of the agent, as is the case in conceptualizations expressed by They've found his bike in the back of a barn (the vague existential) and They've been frying chips here (the inferred existential). The agent may be plural but, moving forward a little, a single object may also be implied. Nevertheless, the other individuals will still be present in the background as potential candidates, and their number will be somehow limited (as opposed to unlimited or expanding infinitely). In an act of communication, this means that we cannot be sure whether the object being referred to is singular or plural. Figure 4 illustrates this type of defocused agent:
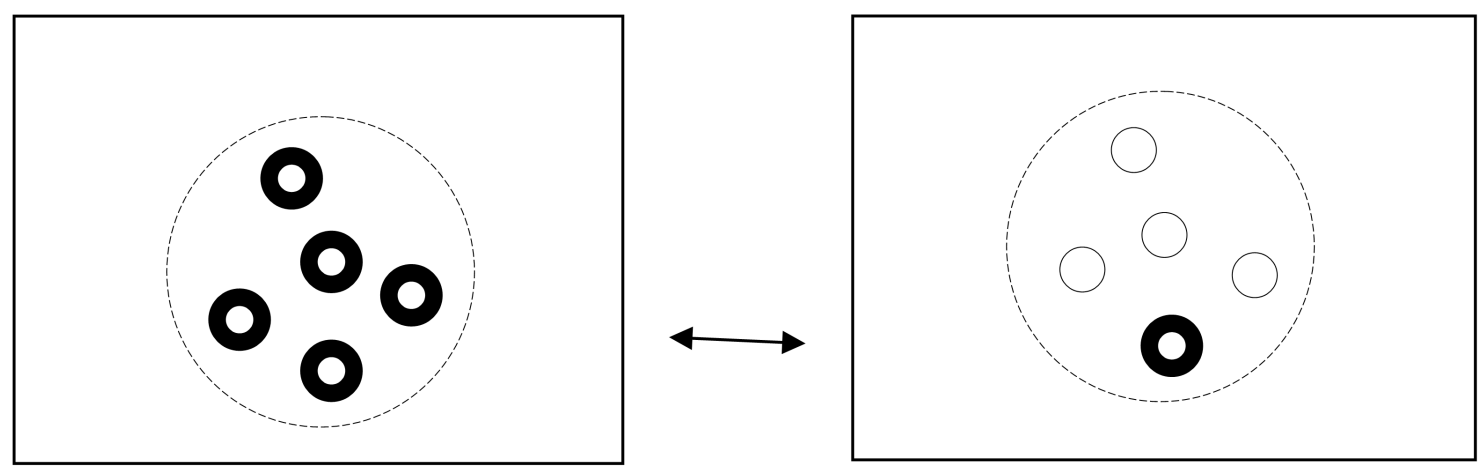

Figure 4: The profile of the agent in the vague or the inferred existential 3pl IMP

This type of agent profile is also confirmed by example (8).

$$
\begin{aligned}
& \text { - Vet ni vad det största problemet är?, } \\
& \text { frågar Eduardo. Allt skräp. De har } \\
& \text { öppnat en Mc Donald's en bit härif- } \\
& \text { rån. Nu ligger det skräp överallt, [...] } \\
& \text { (Etzler, 2006). }
\end{aligned}
$$

\begin{abstract}
- Do you know what the biggest problem is? Eduardo asks. All garbage. They have opened a Mc Donald's a bit from here. Now there is garbage everywhere $[\ldots]$.
\end{abstract}

\title{
5.3 The specific reading
}

The conceptual process of moving closer may continue. One can zoom in further and focus on a single participant by using a singular noun, e.g. a cow. In this case, an obvious similarity to the agent construal in the specific existential reading of the 3pl IMP (as in They're knocking on the door) can be observed. This type of reading is demonstrated in Fig. 5 and exemplified by (9) below.

För mig har de ringt på och sen bara lämnat ett paket utanför dörren, och redan hunnit försvinna som om brevbäraren var självaste batman (krimm, 2009).
For me, they have rung the doorbell and then just left a package outside the door and disappeared, as if the postman was Batman himself.

\footnotetext{
${ }^{6}$ According to Langacker (1987, p. 203), "plurals behave like mass nouns" e.g. a book - books. As plurals "they name the substance without imposing any inherent limitations on its spatial extension" (Langacker, 1987, p. 204). This kind of substance, however, is not homogeneous. It is modular and differentiated. Moreover, it can become bounded within a concrete conceptualization.
} 


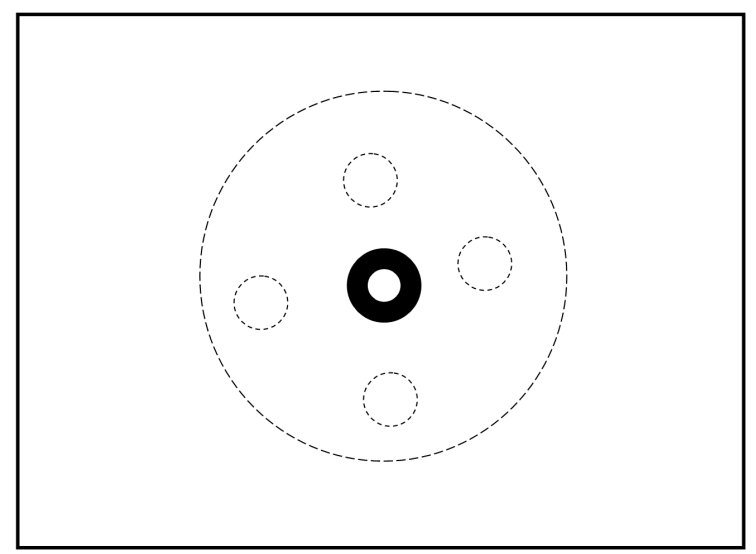

Figure 5: The profile of the agent in the vague specific existential 3pl IMP

\subsection{The universal reading}

Referring back to Fig. 5, it may be added that the conceptualizer can take one more step approaching the object. As Langacker (2006b, p. 122) expresses it, when "I move in for a closer look, and press my nose against the side of" an object - in the present case an individual seen as a human being, "I lose sight of its overall contour". The result is that a continuous substance (i.e. constituted by identical particles that are close together) becomes present in the conceptualizer's field of view. In this way the number of individuals can be expanded to embrace any individual in the class or people in general, which consequently results in "a generalized participant" (Langacker, 2009, pp. 115, 126), typical for the universal reading of the 3pl IMPs (as in In Spain, they eat late). A variant which is clearly connected with this reading is the speech act verb say construction. Both types of impersonal readings are demonstrated by Figure 6 and illustrated by the examples (10) and (11) below.

$$
\begin{aligned}
& \text { - Du, sa jag, vad vet du om svälten i } \\
& \text { Turkana? } \\
& \text { - I Turkana? Svälter de där? } \\
& \text { - Jag tror det. Min redaktör hemma i } \\
& \text { Sverige säger det. [...] } \\
& \text { Turkana alltså där svälter folk som fan } \\
& \text { alltså (Nilsson, 1990, p. 23). } \\
& \text { De säger att tiden läker alla sår men } \\
& \text { de ljuger. Tiden läker ingenting, [...] } \\
& \text { (Sprowede, 2015). }
\end{aligned}
$$

- You, I said, what do you know about the famine in the Turkana District?

- I Turkana? Are they starving there? - I think so. My editor in Sweden says that. [...]

Turkana, then, people are starving like hell there.

They say that time heals all sores, but they lie. Time heals nothing, [...].

In both cases the implied agent can be described as people in general (homogeneous individuals). The conceptualizer then approaches the object, which enables him/her to portray it more generally, defocusing it within the conceptualization. In Langacker's terms such an object encompasses the whole field of view of the conceptualizer, or it is unbounded as it reaches beyond the conceptualizer's field of view. As it is not included in the scope of predication, it is unlimited.

It can be observed that, looking into the agent from the conceptual perspective, certain contextual features (highlighted in Siewierska's and Papastathi's taxonomy (2011) and presented in Table 1 in the initial part of the article) cease to be relevant. The locative expression, featured as a necessary condition for distinguishing the universal reading, may be seen as optional. Two conceptualizations confirming this statement are shown in (12) and (13). 


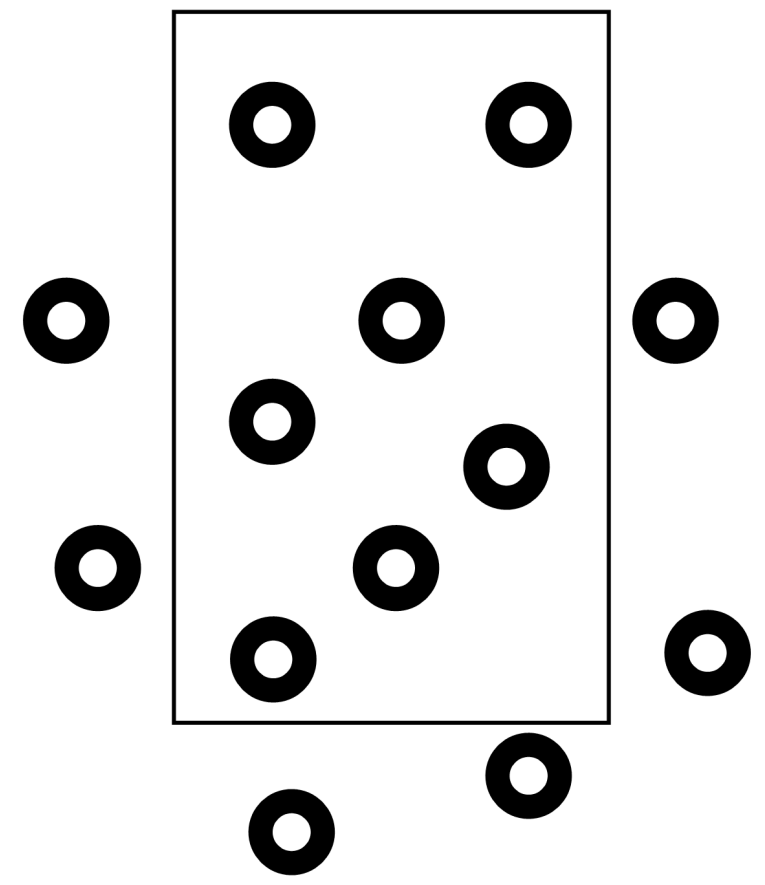

Figure 6: The profile of the agent in the universal reading and the say-construction of the 3pl IMP

\begin{abstract}
Ajdå, den där långpromenaden var kanske inte så bra ändå... [...]De säger här att man ska passa på att vara ute så mycket som möjligt eftersom det fryser ihjäl (?) bacillerna! ("Atjoooo...prosit! $=(. ", 2007)$
\end{abstract}

Well, that long walk might not be great anyway ... [...]They say here to take care to be out as much as possible because it's freezing (?) bacilli!

According to the criteria distinguished by Siewierska and Papastathi (2011), the content is to be interpreted as resembling the universal reading due to the occurrence of the adverb här 'here', even though it includes the quotative verb sager 'say'. Directing attention to the character of the agent and seeing it as a homogeneous substance constituted by identical particles makes it possible to avoid such problems. Both the universal and the quotative say-construction represent a generalized participant (as illustrated by Figure 6 above).

On the other hand, an example clearly resembling the universal reading is mentioned in (13). The expression is the title of a popular children's book:

De kallar mig Tjockis! (De kallar

They call me fatty! mig Tjockis!: En bok för barn om mobbning, 2004)

The pronoun de 'they' clearly implies an agent that can be characterized as generic and paraphrased as folk 'people', yet it is not delimited by a locative. Neither is it anchored in time. Nevertheless, de 'they' takes the picture of a generalized participant as a reference point. The number of individuals seen schematically as human beings is unlimited. Therefore, it may be concluded that the CG view of impersonal readings of the $3 \mathrm{pl}$ pronoun makes it possible to capture several impersonal contents of the pronoun that were difficult to classify within the taxonomy model proposed by Siewierska and Papastathi (2011). 


\section{Concluding remarks}

Langacker $(2009,2011)$ demonstrates how agent defocusing may be treated within the framework of CG, yet a definitive description of the phenomenon has not yet been established. In the present article, such a description is proposed for the 3pl IMPs. The varied readings of the $3 \mathrm{pl}$ impersonal construction have been conceived of as rooted in a cognitively basic mechanism of distancing, a mechanism that has been explained suggestively by the example of Lakoff's cows in the initial part of the paper.

The particular readings of the 3pl IMP (listed by Cabredo Hofherr, 2003 and Siewierska \& Papastathi, 2011) may be ordered as a continuum. Taking the corporate reading as a departure point, the conceptualizer can move nearer and nearer to the perceived object, featuring it in a different manner. Approaching the conceptual content from different vantage points when no specific individuals can be singled out by the 3 pl pronoun, $\mathrm{s} /$ he applies a more general mechanism underlying the creation of the linguistic concepts that may be conventionalized as: a collective noun (e.g. herd), a plural countable noun (cows), a singular noun (a cow) and a homogeneous mass noun (cowness).

The various agent portrayals presented in Figures 3-6 above are cognitively natural reference points within the $3 \mathrm{pl} \mathrm{IMP} \mathrm{category.} \mathrm{The} \mathrm{contextual} \mathrm{factors} \mathrm{presented} \mathrm{by} \mathrm{Siewierska} \mathrm{and} \mathrm{Papastathi}$ (2011) are supportive, but not decisive in distinguishing such portrayals. They help to create a frame, within which the profile of the $3 \mathrm{pl}$ pronoun becomes conceptually clarified. An exhaustive description of such contextual features has, however, not been provided and it may be questioned whether such a description is at all possible. Therefore, the classification of particular types of readings of the $3 \mathrm{pl}$ IMP should be based on the conceptual picture of the agent revealed by the pronoun in a concrete conceptualization. As has been demonstrated, such pictures are not accidental and can be ordered conceptually.

From the point of view of traditional typological descriptions, mainly based on Siewierska and Papasthati (2011), the 3pl IMPs may be arranged as follows: universal/corporate $>$ vague $>$ inferred/specific (Siewierska \& Papastathi, 2011, p. 603). From the perspective of CG, four different types of readings can be distinguished. They are to be organized on conceptual (semantic) grounds as: corporate $>$ vague $>$ specific $>$ universal. They pertain to the conceptual portraits of the defocused agent resembling the profile of a collective noun, a plural countable noun, a singular noun and a homogeneous mass noun. As such, they constitute the most prototypical (clearest) reference points within the continuum. However, due to the fact that peripheries of categories overlap, it is not essential that an agent profile in a concrete linguistic conceptualization should be of one type rather than another. A particular meaning can resemble the neighboring one. For example, in some situations the corporate reading can resemble the vague reading of the 3 pl IMP. It will, however, never show any similarity to the universal reading (as it is postulated in Siewierska's \& Papastahi's model) because the two profiles imply completely different ways of content construal: distant - delimited in the former (a collective noun) and narrow - unlimited in the latter case (a homogeneous mass noun). Similarly, the vague reading cannot be confused with the universal one. They too imply two different types of agent - the modular limited and the homogeneous unlimited, respectively. Therefore, the quotative say-construction expressing a general truth cannot be regarded as a kind of vague reading.

Based upon a general cognitive mechanism that is deeply rooted in people's physical experience and, as such, entrenched in their organization of cognitive structures, the proposed continuum of reference points - different profiles of the agent - may be hypothesized to prove essential in explicating the conceptual organization of readings of the 3pl IMP construction in European languages. 


\section{References}

Bühler, K. W. (1982). Sprachtheorie: Die Darstellungsfunktion der Sprache. Stuttgart: UTB. (1st ed. 1934).

Cabredo Hofherr, P. (2003). Arbitrary readings of third person pronominals. In M. Weisgerber (Ed.), Proceedings of the Conference Sinn und Bedeutung 7 (pp. 81-94). Konstanz: Konstanz University. (Arbeitspapiere des Fachbereichs Sprachwissenschaften, 114). Retrieved August 17, 2019, from https://pdfs.semanticscholar.org/99fc/ac1033d3e9e24c21877179e47cb3c92727c6.pdf

Cabredo Hofherr, P. (2006). 'Arbitrary' pro and the theory of prodrop. In P. Ackema, P. Brandt, M. Schoorlemmer, \& F. Weermann (Eds.), Agreement and arguments (pp. 230-261). Oxford: Oxford University Press.

Data-Bukowska, E. (2018). The third person plural impersonal in Swedish: A typological account. Linguistica Copernicana, 15, 163-193. https://doi.org/10.12775/LinCop. 2018.012

Gast, V. (2015). Final report: 'Towards a typology of human impersonal pronouns' (2012-2015). Retrieved August 17, 2019, from https://www.researchgate.net/publication/286456492_Final_report_ 'Towards_a_typology_of_human_impersonal_pronouns'_2012-2015

Gast, V. \& van der Auwera, J. (2013). Towards a distributional typology of human impersonal pronouns, based on data from European languages. In D. Bakker \& M. Haspelmath (Eds.), Languages across boundaries: Studies in the memory of Anna Siewierska (pp. 119-158). Berlin: Mouton de Gruyter.

Langacker, R. W. (1987). Foundations of cognitive grammar: Vol. 1. Theoretical prerequisites. Stanford, CA: Stanford University Press.

Langacker, R. W. (1991). Foundations of cognitive grammar: Vol. 2. Descriptive application. Stanford, CA: Stanford University Press.

Langacker, R. W. (2004). Grammar as image: The case of voice. In B. Lewandowska-Tomaszczyk \& A. Kwiatkowska (Eds.), Imagery in language: Festschrift in honour of Professor Ronald W. Langacker (pp. 63-111). Frankfurt am Main: Peter Lang.

Langacker, R. W. (2006a). Dimensions of defocusing. In T. Tsunoda \& T. Kageyama (Eds.), Voice and grammatical relations (pp. 115-137). Amsterdam: John Benjamins. https://doi.org/10.1075/tsl. 65.081 an

Langacker, R. W. (2006b). On the continuous debate on discreteness. Cognitive Linguistics, 17(1), 107-151. https://doi.org/10.1515/COG.2006.003

Langacker, R. W. (2009). On the subject of impersonals. In R. W. Langacker, Investigations in cognitive grammar (pp. 109-147). Berlin: Mouton de Gruyter. https://doi.org/10.1515/9783110214369.109

Langacker, R. W. (2011). On the subject of impersonals. In Z. Fuchs, S. T. Gries, \& M. Brdar (Eds.), Cognitive linguistics: Convergence and expansion (pp. 179-217). Amsterdam: Benjamins.

Myhill, J. (1997). Towards a functional typology of agent defocusing. Linguistics, 35(5), 799-844. https: //doi.org/10.1515/ling.1997.35.5.799

Siewierska, A. (2008). Ways of impersonalizing: pronominal vs. verbal strategies. In M. de los Angele Gómez González, J. Lachlan Mackenzie, \& E. M. Gonzáles Álvarez (Eds.), Current trends in contrastive linguistics: Functional and cognitive perspectives (pp. 3-26). Amsterdam: John Benjamins. https: //doi.org/10.1075/sfsl.60.03sie

Siewierska, A. (2011). Overlap and complementarity in reference impersonals: Man-construction vs. third person plural-impersonals in the languages of Europe. In A. Malchukov \& A. Siewierska (Eds.), Impersonal constructions: A cross-linguistic perspective (pp. 57-89). Amsterdam: John Benjamins. https://doi.org/10.1075/slcs.124.03sie

Siewierska, A., \& Papastathi, M. (2011). Third person plurals in the languages of Europe: Typological and methodological issues. Linguistics, 43(2), 575-610.

Teleman, U., Hellberg, S., \& Andersson, E. (1999). Svenska Akademiens Grammatik. Vol. 2 Ord. Stockolm: Notrstedts Ordbok.

\section{Sources}

Atjoooo...prosit! =(. (2007, January 24). Retrieved August 17, 2019, from https://www.resdagboken. $\mathrm{com} / \mathrm{p} / 1033513$-atjoooo-prosit

Cowness. (n.d.). In Wiktionary. Retrieved August 17, 2019, from https://en.wiktionary.org/wiki/ cowness 
De kallar mig Tjockis!: En bok för barn om mobbning. (2004). Retrieved August 17, 2019, from https: //www.bokus .com/bok/9789173170437/de-kallar-mig-tjockis-en-bok-for-barn-om-mobbning/

Etzler, A. (2006, August 30). Knacka dörr. Flamman. Retrieved August 17, 2019, from http://flamman . $\mathrm{se} / \mathrm{a} / \mathrm{knacka-dorr}$

krimm. (2009, November 27). [Blog comment]. Retrieved August 17, 2019, from https ://www.flashback. org/t1063701

Mr_Big. (2012, April 16). [Blog comment]. Retrieved August 17, 2019, from http://www.mestmotor.se/ bilsnack/forum/archive/index.php/t-381652.html

Nilsson, B. (1990). En bil ait mister Singh: Roman. Stockholm: Bonnier. Retrieved from https://books.google.pl/books?id=BKHCDgAAQBAJ\&pg=PT17\&lpg=PT17\&dq=sv\%C3\%A4lter+ de\&source=bl\&ots=0futVCYy9Z\&sig=ppxW9jWTQ0i8f0-VLUN896mx7ec\&hl=pl\&sa=X\&ved= OahUKEwiOy-mS76zVAhXFa5oKHRYSAC84ChDoAQglMAA\#v=onepage\&q=sv\%C3\%A4lter\%20de\&f $=$ false

Sprowede, B. (2015, April 2). [Facebook post]. Retrieved August 17, 2019, from https://www.facebook. $\mathrm{com} /$ sprowede/posts/1484527735122402

Täcker hemförsäkringen stulna nycklar? [Blog post]. (2010, August 12). Retrieved August 17, 2019, from http://www.familjeliv.se/forum/thread/53939501-tacker-hemforsakringen-stulna-nycklar

Ytterligare en skatt på elektronik... vad håller de på med? (2017). Retrieved August 17, 2019, from https://www.reddit.com/r/sweden/comments/5ye0ti/nu_\%C3\%A4r_kemikalieskatten_p \%C3\% A5_elektronik_klubbad/?st=j9vqpbv2\&sh=3176bb21

This work was financed by the Polish Ministry of Science and Higher Education.

The author declares that she has no competing interests.

This is an Open Access article distributed under the terms of the Creative Commons Attribution 3.0 PL License (http://creativecommons.org/licenses/by/3.0/pl/), which permits redistribution, commercial and noncommercial, provided that the article is properly cited.

(C) The Author 2019

Publisher: Institute of Slavic Studies, Polish Academy of Sciences 